AIAA 2001-5079

\title{
FEANICS - A MULTI-USER FACILITY FOR CONDUCTING SOLID FUEL COMBUSTION EXPERIMENTS ON ISS
}

\author{
David T. Frate \\ NASA Glenn Research Center \\ Cleveland, Ohio \\ Todd A. Tofil \\ NASA Glenn Research Center \\ Cleveland, Ohio
}

\begin{abstract}
The Destiny Module on the International Space Station (ISS) will soon be home for the Fluids and Combustion Facility's (FCF) Combustion Integrated Rack (CIR), which is being developed at the NASA Glenn Research Center in Cleveland, Ohio. The CIR will be the platform for future microgravity combustion experiments. A multi-user mini-facility called FEANICS (Flow Enclosure Accommodating Novel Investigations in Combustion of Solids) will also be built at NASA Glenn. This mini-facility will be the primary means for conducting solid fuel combustion experiments in the CIR on ISS. The main focus of many of these solid combustion experiments will be to conduct basic and applied scientific investigations in fire-safety to support NASA's Bioastronautics Initiative. The FEANICS project team will work in conjunction with the CIR project team to develop upgradeable and reusable hardware to meet the science requirements of current and future investigators. Currently, there are six experiments that are candidates to use the FEANICS mini-facility. This paper will describe the capabilities of this mini-facility and the type of solid combustion testing and diagnostics that can be performed.
\end{abstract}

\section{Introduction}

The Combustion Integrated Rack will be the primary facility for conducting microgravity combustion experiments on the International Space Station. In order to utilize this facility most effectively, the NASA Glenn Research Center is planning on building several "mini-facilities" in order to perform combustion research ${ }^{1}$. The mini-facilities will consist of a piece of

Copyright $\odot 2001$ by the American Institute of Aeronautics and Astronautics, Inc. No copyright is asserted in the United States under Title 17, U.S. Code. The U.S. government has a royalty-free license to exercise all rights under the copyright claimed herein for Governmental Purposes. All other rights are reserved by the copyright owner. hardware that is inserted into the combustion chamber in the CIR as well as any of the diagnostics and consumables (fuels, gases, etc.) that would be necessary to perform the required tests. The mini-facility hard ware, combined with the hardware provided by the CIR, is intended to meet the science requirements of the individual experiments. The first of these minifacilities will be the Multi-user Droplet Combustion Apparatus (MDCA), which will be available for investigators to study the burning of liquid fuels in the form of droplets ${ }^{2}$. The second mini-facility will be the Flow Enclosure Accommodating Novel Investigations in Combustion of Solids (FEANICS). This apparatus will provide the hardware needed to study combustion of both thick and thin solid fuels in microgravity. The last currently planned mini-facility is the Multi-user Gaseous Fuel Apparatus (MGFA). This facility will focus on the combustion of gaseous fuels in the $\mathrm{CIR}^{3}$.

The FEANICS mini-facility will consist of two separate CIR chamber inserts. One will be designed to study combustion of thin fuels. The other will be designed to study combustion of thick fuels. The centerpiece of both inserts will be a flow tunnel in which the combustion process will take place. The flow tunnel will allow for testing at various flow velocities, in concurrent or opposed flow, or at quiescent conditions. The tunnel will also have a filter section to clean the by-products of combustion. In order to save on gas usage, and consequently upmass and stowage volume. the inserts will utilize a gas recirculation approach in conjunction with the CIR to bleed in oxygen to replenish the amount consumed from combustion. Hence, once gas passes through the flow tunnel and the combustion zone, it is then filtered, dumped into the

This is a preprint or reprint of a paper intended for presentation at a conference. Because changes may be made before formal publication, this is made available with the understanding that it will not be cited or reproduced without the permission of the author. 

CIR chamber, and then mixed with fresh oxygen before it is re-introduced into the tunnel inlet.

Because the FEANICS facility is being designed to study ignition, flame spread, and extinguishment of flames on solids, it is uniquely capable of supporting the fire-safety research required by NASA's Bioastronautics Initiative. This Initiative was begun in 2001 to ensure and enhance the health, safety, and performance of humans in space. In addition to the many physiological and psychological affects of longduration space flight on the success of a space mission, providing a fire-safe environment in which astronauts live and work is one of the focus areas of this Initiative.

The types of investigations that will be made possible in the FEANICS insert are important, not only to increase basic understanding of the combustion of solids, but also to provide very practical data about firesafety in spacecraft. For example, all materials that are qualified for use in a space vehicle undergo flammability testing using several standard tests in $1-\mathrm{g}$. These tests are generally pass/fail, with materials that pass being approved for use in spacecraft. Essential materials that fail the test, such as paper or cotton clothing, can be given flight waivers that outline specific storage, handling, and disposal requirements.

Based on data obtained in microgravity and experience gained from the beginning of the U.S. manned space program, these normal gravity flammability assessments have been assumed to be conservative with respect to flammability in all environments. However, some of the complex interactions that govern ignition and flame growth can only be evaluated in the long durations of microgravity available on the ISS. An increased understanding of combustion of solids that will be made available by FEANICS will greatly enhance the ability to assess material flammability in microgravity and provide increased confidence in current spacecraft fire protection policies and procedures that is not possible in ground-based tests. There are currently six investigators that are planning to use the FEANICS hardware to evaluate various aspects of solid combustion. Many of these have objectives that relate directly to improving fire-safety on spacecraft. Their experiments are:

- Forced Ignition and Spread Test (FIST) with Principal Investigator (PI) Carlos FernandezPello

- Solid Inflammability Boundary at Low-Speed (SIBAL) with PI James T'ien

- Radiative Enhancement Effects on Flame Spread (REEFS) with PI Paul Ronney
- Transition from Ignition to flame Growth under External Radiation in Three Dimensions (TIGER-3D) with PI Takashi Kashiwagi

- Analysis of Thermal and Hydrodynamic Instabilities in Near-limit Atmospheres (ATHINA) with PI Indrek Wichman

- Smolder, Transition and Flaming in Microgravity (STAF) with PI Carlos Fernandez-Pello

These experiments will conduct basic research to advance our knowledge of the combustion of solids as well as applied research that specifically addresses firesafety in spacecraft.

\section{CIR Interfaces and Diagnostics}

The FEANICS experiment has structural, electrical power, cooling, data, control, and gaseous supply interfaces with the CIR ${ }^{4}$. The CIR will also provide several optical diagnostics packages that FEANICS will utilize.

\section{Optical Diagnostics}

The optical diagnostic packages will be located outside of the combustion chamber and at any of the eight Universal Mounting Location (UML) positions. Each UML will be aligned with a chamber window and separated by 45 degrees around the circumference of the chamber. The chamber windows will be sapphire. FEANICS will develop any required optical diagnostic packages that are not provided by CIR. Currently, the imagers provided by CIR, that FEANICS is planning on using, are the Low Light Level Ultraviolet (LLL-UV), Low Light Level Infrared (LLL-IR), and color cameras. CIR will only provide one of each of these cameras. If more than one is required for a specific experiment, the cost and resources for flying that camera are book kept with that particular investigation. The only additional diagnostic package that FEANICS is currently planning to develop is the mid-infrared (mid-IR) camera. During operation, each imager is paired with an Image Processing and Storage Unit (IPSU) for temporary digital data storage before it is downlinked to the ground.

The LLL-UV is a short wave intensified imager that can be used for imaging over the spectrum of 220 to $850 \mathrm{~nm}$ where, for example, $\mathrm{OH}$ emissions can be measured. The LLL-IR is a long wave intensified imager that can be used for imaging over the spectrum of 400 to $900 \mathrm{~nm}$ where, for example, $\mathrm{H}_{2} \mathrm{O}$ emissions can be measured. A zoom lens will be provided with this camera. Motorized focusing and auto iris adjustments will also be possible. The color camera will operate in the visible spectrum, from 400 to 700 

$\mathrm{nm}$. It will be equipped with an auto-iris and motorized focus. This camera will typically be used to image the flame shape, color, and spread rate.

The FEANICS-built mid-IR camera will have a detection range of 3000 to $5000 \mathrm{~nm}$. The primary planned use for this camera will be to view the fuel surface during combustion to get a measurement of the fuel temperature. A flame filter with a bandpass in the range of 3700 to $4100 \mathrm{~nm}$ will be provided so that the fuel surface can be viewed without interference from the flame.

\section{Fluid Interfaces}

The CIR's Fuel and Oxidizer Management Assembly (FOMA) can be used to supply oxidizer, diluents, ISS nitrogen, or gaseous fuels into the combustion chamber. The FOMA also provides a gas chromatograph (GC) and an overboard vent interface to the chamber. The physical interface for all of these fluid lines with the chamber is at the Interface Resource Ring (IRR), which is located inside the chamber, near the lid.

Gas can be delivered form FOMA into the chamber from $1,2.25$ and 3.8 liter bottles. The CIR will provide FEANICS with empty bottles that can be filled with oxygen/diluent mixtures up to $85 \%$ oxygen (only the Iliter bottles), or gaseous fuels. These bottles are physically compatible with the FOMA system which can deliver them into the chamber or mix them and then deliver them to the chamber. FEANICS will fill these bottles with the correct mixtures in order to carry out the specific test matrices for each investigation. A quick disconnect fluid port is provided for adding oxidizer to the chamber at the IRR. FEANICS will use this port to add $85 \%$ oxygen to the chamber to maintain a constant oxygen level throughout the combustion process. Bottle quantity affects experiment upmass, volume and stowage, all of which are limited resources on the ISS. Future investigators should try to minimize the amount of gas needed when developing their test matrices.

In order to aid in minimizing the amount of gas required, a recirculating approach will be used for gas flow between the flow tunnel and the CIR chamber. This will include real-time monitoring and control of oxygen concentration. The FOMA gas bottles will be used to bleed in fresh oxidizer to the chamber in order to maintain a constant oxygen level in the flow tunnel during combustion. As the combustion process proceeds and the by-products of combustion fill the chamber, the chamber's oxygen level would decrease without new oxidizer supplied. The control system will monitor the oxygen level in the chamber, compare the actual level to the desired level, and add oxidizer to achieve the desired oxygen level.

Since oxidizer is added during a test, simultaneous realtime overboard venting will be required to maintain a constant chamber pressure. The CIR's FOMA will maintain this pressure. Prior to venting overboard, the combustion by-products must be cleaned to certain levels. FEANICS is planning on performing the filtering in the flow tunnel to meet these levels. The FOMA also offers an Exhaust Vent Package (EVP) for post-test clean-up. This will not work for FEANICS since real-time venting is needed. The maximum oxygen concentration that can be vented overboard is $30 \%$; therefore, that is the upper limit for testing with FEANICS when there is flow. For quiescent testing, a maximum of $50 \%$ oxygen can be used. In this case, the chamber contents can be diluted prior to venting after the test.

A GC port interface is provided at the IRR that may be used for scientific evaluation of the chamber gases or for verifying the chamber atmosphere before venting. Since FEANICS is venting real-time, GC analysis for vent verification will not be possible. It is best suited for pre- or post-test analysis for FEANICS.

The FOMA system will have a connection to the ISS gaseous nitrogen resource. This resource will be available for adding gaseous nitrogen to the chamber. FEANICS will require the use of station nitrogen to support its operations. Station nitrogen will be used to backfill the chamber after an evacuation, before a chamber access, and to dilute the $85 \%$ oxygen $/ 15 \%$ nitrogen gas mixture in the FEANICS gas bottles to the desired test concentration. Roughly $5 \mathrm{lbs}$ of nitrogen will be available to each investigator.

\section{Environmental Control System (ECS)}

The Environmental Control System (ECS) will provide air cooling to the FEANICS avionics box and optical diagnostics on all of the UML's. It will also supply water cooling to the interior of the chamber. Water cooling to components inside the chamber will be provided via inlet and outlet ports on the IRR. Watercooling at the UML's is not currently available. A total of $450 \mathrm{~W}$ of heat rejection through air, and $500 \mathrm{~W}$ through water cooling will be available based on the design presented at the FCF Preliminary Design Review (PDR) in February 2001. FEANICS is not planning on providing any active cooling to the gases flowing through the tunnel. CIR advertises that the FOMA gases will be in the range of 290 to $301 \mathrm{~K}$. 

Electrical Interfaces

The FEANICS avionics box (main computer and control box) will receive power from the CIR Electrical Power and Control Unit (EPCU). Individual UML locations also receive power from the EPCU. The EPCU delivers $443 \mathrm{~W}$ to the avionics box and an additional $443 \mathrm{~W}$ to the hardware components inside the chamber, according to the PDR design.

Additionally, $1440 \mathrm{~W}$ at $120 \mathrm{dc}$ are available through an interface in the CIR rack. This power will be conditioned and used to power the higher powered components for FEANICS such as the $\mathrm{CO}_{2}$ laser and radiant heater.

Command and data interfaces with the CIR include an Ethernet connection for command and control of the FEANICS avionics box by the CIR Input/Output Processor (IOP). This will allow for commanding the experiment from the ground as well and provide a means for communication between the chamber insert hardware, the avionic box, and the CIR data processing and storage.

\section{Structural Interfaces}

The structural interfaces exterior to the chamber for the avionics box, laser, and optical diagnostics are on the CIR optical bench. These interfaces are the UML's. Eight positions are available around the chamber circumference.

Four cylindrical rails are located along the interior walls of the chamber. They provide a means to secure the insert and to establish a known position relative to the chamber windows. FEANICS will use two rails for mounting. Additionally, axial-locating holes will be provided in the chamber that are located at a fixed distance from the window centerline. A locating pin attached to the FEANICS inserts will interface with that hole to fix the insert's position in the chamber.

A mixing fan will be provided in the rear of the CIR chamber. FEANICS will remove the fan and replace it with a blank section if additional room for the insert is needed. Otherwise, it could be used to assist in mixing the fresh oxygen to the chamber gases.

\section{Insert for Thin Fuel Testing}

The thin fuel insert will be comprised of a suite of hardware that will form the mini-facility. The main component of the thin fuel mini-facility hardware will be the chamber insert. The chamber insert will slide into the combustion chamber by making use of the rails in the chamber. This will allow the insert to also be partially removed and locked in place for maintenance or hardware change out by the crew. The main feature of the insert will be a flow tunnel. The flow tunnel will be the location where the combustion tests take place. Attached to the flow tunnel will be either one of two fuel delivery mechanisms. An end-loader mechanism will allow for testing of single, thin fuel sheets. A fuel roll mechanism will allow for testing of a continuous roll of flexible fuel. In addition to the insert, there will also be an avionics box that will serve as the main computer for control of the insert. This box will be located outside the CIR combustion chamber. The avionics box may also be used to store or manipulate a limited amount of data. The SIBAL and TIGER 3-D experiments are planning on using this insert.

To switch from one experiment to another, some components will be removed and some will be added to obtain the needed hardware arrangement. The goal for the FEANICS design is to minimize the astronaut time and parts needed to go from a given experiment's configuration to the next experiment's configuration. Common components include the tunnel, fan section, filter section, and mounting rails. Experiment specific items will be the fuel delivery systems and instrumentation. Filters, tunnel windows and fuel delivery systems will be on-orbit replaceable items.

Additional hardware items needed to interface with or operate the insert are also provided by FEANICS, including but not limited to oxygen sensor(s), instrumentation for measuring test conditions, all cabling within the chamber and between the chamber and the avionics box.

\section{Flow Tunnel}

The chamber insert will include a flow tunnel assembly, including filters, flow straighteners, a fan section and instrumentation. The flow tunnel will be $12 \mathrm{~cm}$ high $x$ $15 \mathrm{~cm}$ wide $\times 30 \mathrm{~cm}$ long. It will be constructed such that the fuel is positioned in the center of the tunnel, which will be centered on the centerline of the CIR chamber. The four sides of the tunnel are replaceable windows. The window materials will be selected to suit the optical diagnostic requirements. The frame of the tunnel will be black-anodized aluminum.

Honeycomb and screen flow straighteners will be employed in the tunnel in order to achieve uniform flow at the tunnel inlet. The flow tunnel will support both concurrent and opposed flow for fuels centered in the chamber. For the single sheet end-loader mechanism, this is accomplished by changing the ignition position on the fuel sample, since flow will be possible in only one direction. For the fuel roll mechanism, the direction of the fuel motion can be reversed to create opposed or concurrent flow. 
Several small fans will be used to provide the required flow conditions. Multiple fans are used because the rolled fuel splits the tunnel into two sections along the long axis. A slot is required in the center of all components in the tunnel.

The fans will be used at the exit end of the tunnel, downstream of the filter section, to pull air through the tunnel and filter to attain the flow velocity required. The achievable flow velocity range will be $0-20$ $\mathrm{cm} / \mathrm{sec}$. It will be controllable in discrete increments. Velocity control in the tunnel will be achieved by either calibrating the fan voltage to velocity or by measuring and controlling the rpm's of each fan. There may also be real time measurement of the flow velocity and possible feedback to the fans to account for changes in flow due to the presence of the flame and the increased pressure drop in the filter section over time. Further testing needs to be completed before the final method is determined.

A replaceable filter section will be located at the exit end of the tunnel, between the tunnel test section and the fan section. The filter design is in its early stages. Possible filter materials include lithium hydroxide (LiOH), molecular sieve, sofnocat, and activated carbon and will most likely be a combination of several of these materials as required by the specific experiments. The filter section will remove the unwanted combustion by-products including carbon monoxide, carbon dioxide, water, and various hydrocarbons before the test gas is recirculated into the chamber.

Permanent instrumentation in the tunnel will consist of oxygen sensors and some yet-to-be-defined method to measure velocity. The oxygen sensors will be of the Zirconia type and in addition to providing data they are used for controlling the oxygen makeup in the tunnel. Gas inlet and exit temperatures will also be measured. There will also be a thermocouple rake to measure gas temperatures near the flame during a test.

The flow tunnel will have windows on four sides to allow imaging of the combustion process. The windows will be replaceable on-orbit for the purposes of obtaining a configuration of windows that is compatible with the experiment-specific cameras and requirements. It will also facilitate the cleaning of the windows, if necessary. Windows that are currently planned for this insert are two fused silica windows and a ClearTran window. The fuel surface view will be the ClearTran window in order to accommodate the laser ignition system described below. Other windows may be provided if needed.

\section{Fuel Roll Delivery System}

For investigators who prefer to burn a flexible fuel that can be stored on a roll, a fuel roll delivery system will be provided by FEANICS. The advantage of this approach is that it facilitates long test times. One application of this benefit is to study flammability boundaries. The long burn times allow for gradual changes in test conditions such as flow velocity or oxygen concentration in approaching the boundary. The maximum fuel width that is attainable with this mechanism is approximately $13 \mathrm{~cm}$. In order to roll up the fuel after the test, there must be a non-combustible edge to the fuel; hence the maximum fuel width is less than the tunnel width of $15 \mathrm{~cm}$.

The fuel roll mechanism will allow for the use of a continuous roll of thin fuel located at the tunnel centerline. On one end of the tunnel, but positioned back several centimeters to allow gas to enter the tunnel, there will be a fuel take-up spool and stepper motor assembly. On the other end, positioned away from the tunnel opening to allow for the gas exit, there will be a fuel supply spool and stepper motor assembly. Figure 1 displays the thin fuel insert with the fuel rolls. This mechanism, in conjunction with some image feedback from one of the diagnostic cameras, will feed the fuel roll into the flame at the same speed as the flame spread rate. This will keep the flame stationary with respect to the diagnostics (and windows) and allow for long duration testing. The camera will track the flame position and that information is sent to the spool motors to make the adjustments. This technique has been demonstrated successfully using an IR camera viewing the fuel surface. By changing the direction of the fuel motion, opposed or concurrent flow is possible. There will be testing in the future to determine if a color camera viewing the edge of the fuel will also work for flame tracking.

The current fuel used in this fuel system is a cellulose/fiberglass weave. The length of fuel that can be put on a spool is dependant on the fuel thickness. The current design indicates that almost $900 \mathrm{~cm}$ of a 0.1 $\mathrm{cm}$ thick fuel can be placed on a supply roll. Since the fuel is on a roll, no instrumentation, such as fuel surface thermocouples will be possible.

Replacing the fuel roll is a complex activity that will be performed by an astronaut. In the case of concurrent flow testing, the astronaut will pull the insert partially out of the chamber, remove the roll with the burned fuel (take-up spool) and splice it to a roll of new fuel. The insert is then placed back in the chamber. The new fuel roll would then have to be rewound onto the supply spool. 

End-loader Fuel Delivery System

The end-loader fuel changeout mechanism will be a cartridge type end-loader. Multiple thin fuel samples will be individually contained within the end-loader to ensure containment of burned material. A sample holder supports each fuel sample. The current concept will accommodate 6 fuel samples which are $1 \mathrm{~cm}$ thick. More samples could be accommodated with thinner samples and fewer with thicker samples. The fuel samples will be "stacked" in the end-loader, which will be located on the end of the flow tunnel near the chamber door, opposite the filter and fan sections. Figure 2 displays the thin fuel insert with the endloader. In the end-loader, the fuel to be burned will be initially located so that the fuel is outside of the tunnel, but at the centerline position. As with the rolled fuel configuration, slots in the inlet section are required for access to the tunnel. A motor and ball screw mechanism will move the fuel in the holder along guide rails into the tunnel. When the fuel is at the burn location, the motor will reverse and pull the screw out, leaving the fuel in the holder. After ignition and combustion are completed, the motor and screw mechanism will activate and the burned fuel will be pulled out of the tunnel and back into the end-loader housing. A second motor will move the entire fuel stack up one position, which simultaneously moves the burned fuel above the centerline position and aligns the next sample with the ball screw. The maximum fuel size for the end-loader will be $17.8 \mathrm{~cm}$ long and approximately $14 \mathrm{~cm}$ wide. Since samples are stored in slots and must move in and out of the chamber, instrumentation on the sample will be limited.

An astronaut will replace the cartridge of burned fuel. The astronaut will pull the entire insert partially out of the chamber, open the end-loader, remove the burned fuel cartridge, then replace it with a new fuel cartridge. The end-loader motors and mechanisms will not need to be changed.

\section{Laser Ignition}

A $10.6 \mu \mathrm{m}, 25 \mathrm{~W}$ (prior to transmission losses), carbon dioxide $\left(\mathrm{CO}_{2}\right)$ laser located outside of the chamber will perform ignition of the FEANICS fuels. The laser will be pointed through a zinc selenide chamber window and the ClearTran tunnel window, although these can be changed to suit other requirements. The zinc selenide window may have to be developed by FEANICS since the CIR is currently only providing sapphire windows. The laser beam will impinge on the sample in the form of a circle approximately $6 \mathrm{~mm}$ in diameter. Spot ignition on the fuel surface is then achieved. The chamber window opposite the laser position is replaced or covered to contain the beam if it burns through the sample. Laser output power will be measured during ignition.

\section{Avionics Box}

The goal is to use a common avionics box for all of the experiments using an insert, and each insert will have a unique avionics box. It will contain power conversion electronics, motor control boards, fan control electronics, signal conditioning, and other electronics to run the experiments and also to interface with the CIR. The avionics box will also contain connectors for interfacing with the CIR facility components. The FEANICS power system will be compatible with the power being delivered from the CIR and their EPCU. The current intent is that on-orbit re-configuring of the avionics box will not be required, although this may change.

The avionics box will mount on a UML and will be aircooled. The CIR chamber's interface resource ring is the where the avionics box and the FEANICS components within the chamber are linked.

\section{Insert for Thick Fuel Testing}

Associated with the thick fuel insert will be a suite of hardware, different from the thin fuel insert, which will form the mini-facility. The main component of the thick fuel mini-facility hardware will also be the chamber insert. The chamber insert will also slide into the combustion chamber by making use of the rails in the chamber. The main feature of the insert will be a flow tunnel. The flow tunnel is intended to be the same design as the thin fuel insert, with the exception that the tunnel sections do not need to be slotted to accommodate a fuel centered in the tunnel. This will reduce the overall design costs for FEANICS by making as much of the hardware common for both inserts. Attached to the flow tunnel will be a multisided fuel carousel delivery system. This carousel will house the fuel samples and introduce them into the flow tunnel for testing. This mini-facility will also have a unique avionics box located outside the CIR combustion chamber. An optional-use radiant heater will also be developed by FEANICS that can be used to heat the fuel samples. FIST, REEFS, ATHINA, and STAF are currently planning on using this insert.

\section{Flow Tunnel}

The thick fuel insert contains a $12 \mathrm{~cm}$ high by $15 \mathrm{~cm}$ wide by $30 \mathrm{~cm}$ long flow tunnel (same as the thin fuel insert tunnel). These dimensions represent the internal flow tunnel test section. The tunnel walls will be composed of replaceable windows attached to a black anodized aluminum framework. The windows will be removable so that the proper window material can be 

put into the position that is compatible with the diagnostic instrument viewing the combustion event from that direction. It will also simplify cleaning of windows. This flow tunnel will have three walls that are windows: the top and both sides. The fuel carousel occupies the bottom of the tunnel; consequently, the bottom of the fuel surface is not available for viewing. The type of tunnel window materials currently planned to be offered by FEANICS in this insert are fused silica IR grade and calcium fluoride. Other materials may be provided if needed.

The flow tunnel will have several other sections which will aid in providing a controlled and uniform flow velocity. At the tunnel inlet, there will be some flow straighteners in the forms of screens and honeycomb. These will help ensure uniform streamlines in the tunnel. At the exit end of the tunnel, there will also be screens as well a section containing a number of fans that will regulate the flow velocity in the tunnel. The fans will be used to "pull" the gas from the inlet to the outlet of the tunnel. Velocity control in the tunnel will be achieved by one of the same methods as the thin fuel insert tunnel mentioned above. The range of velocities possible in the flow tunnel will also be 0 to $20 \mathrm{~cm} / \mathrm{s}$. Flow will always be in one direction in the tunnel. However, both opposed and concurrent flow testing can be accommodated by igniting the fuel at opposite ends.

Immediately following the exit end of the test section in the flow tunnel, there will be a filter section. Since this apparatus will utilize a recirculated gas method for providing flow, it is very important that the postcombustion by-products are cleaned before the gas is re-introduced into the flow tunnel. Recycled byproducts would tend to confound the scientific studies. A comprehensive program will begin later this year to evaluate the effectiveness of various filter materials to filter out the primary combustion by-products of carbon monoxide, carbon dioxide, water, and various hydrocarbons. The filter section will be designed to be replaceable on-orbit by the crew in the event that they become filled beyond the point where the fans can meet the flow velocity requirements. The filter section can also be custom packed for each experiment so that they can best clean the by-products generated from the experiment-specific fuel material and test conditions.

The flow tunnel will also include a retractable thermocouple rake that can be used to measure the gas phase temperature in or near the flame zone. It will be designed to not interfere with the flow while not in use in the retracted position. When in use, the thermocouples will move into the flow.
Fuel Carousel

The fuel samples will be inserted and held in place for testing at the bottom of the flow tunnel. The top surface of the fuel sample will be flush mounted with the floor of the tunnel when fully inserted so that there is no flow disturbance due to the sample. This fuel surface will also be aligned with the centerline of the CIR chamber to accommodate edge views through the chamber windows for cameras or other diagnostics. The fuel samples will be stored in a fuel carousel. This carousel can have from 3 to 7 sides depending on the width of the fuel sample. Figure 3 displays the thick fuel insert and fuel carousel mechanism. Figure 4 shows the end view of this insert with a 7 -sided carousel. A radiant heater is also shown in both figures above the flow tunnel, but that is removable for experiments that do not need it. As the fuel width increases, the number of samples that can be installed on the carousel decreases. For example, $3 \mathrm{~cm}$ wide samples can be placed on a 7 -sided carousel, while 12 $\mathrm{cm}$ wide fuel samples can only be placed on a 3-sided carousel. The advantage of the narrower fuels is that more samples per carousel can be accommodated which is a large benefit in reducing the number of times that the astronaut crew needs to access the chamber. This is important since crew time is a precious resource for conducting experiments on ISS. It also reduces the number of carousels needed to perform the experiment, which reduces the upmass and stowage volume. The maximum fuel size possible in a fuel carousel is $12 \mathrm{~cm}$ wide by $20 \mathrm{~cm}$ long by $1.5 \mathrm{~cm}$ thick.

The carousel will have two motors which will actuate the necessary motion to introduce each sample into the tunnel. There will be a translation motor that will move the entire carousel upwards to mate and form a seal with the tunnel floor prior to a test, and then it will translate downward after a test. The rotation motor will be used to turn the burned sample away from the tunnel floor entrance and introduce a fresh sample that can then be raised into the tunnel by the translation motor. The entire carousel mechanism will be enclosed in a shroud which will help contain the burned fuel samples which may have a tendency to break off the sample. It will also help keep the crew isolated from these samples as well as reduce the odor from combustion.

Ignition of the fuel samples will be accomplished by a hot wire igniter which can be mounted either on the fuel (for direct ignition) or next to the fuel (for ignition of the fuel vapor). Each fuel sample will have an igniter. Other instrumentation of the fuel is also possible with the carousel-mounted fuels. For instance, fuel surface mounted thermocouples may be used. One limitation is the location of this instrumentation. All fuel instrumentation needs to be within $4 \mathrm{~mm}$ of the surface 
so that it does not interfere with the carousel rotation. There is also a limit to the number of wires for instrumentation that can be routed inside the carousel. The specific carousel will determine the limit based on its number of sides.

\section{$\underline{\text { Radiant Heater }}$}

FEANICS will also be building a radiant heater that can be used to pre-heat fuel samples prior to and/or during the ignition process as well as during the flame spreading process. This radiant heater will consist of a quart 2 halogen bulb rated at $1000 \mathrm{~W}$ emitting in the 400 to $3000 \mathrm{~nm}$ wavelength range. The bulb will be positioned in front of a parabolic surface that helps provide a uniform radiant heat flux over the width of the fuel sample. The radiant heater will require water cooling which will be provided from the CIR IRR. The FEANICS team will also be looking at a couple of ways to provide a varying heat flux over the length of the sample surface. One option is to tilt the heater and the other is to use a gradient mirror. The heater will be affixed just above the top tunnel window so that it can radiate to the sample surface. The radiant heater will also be equipped with a filter that will reduce transmission under $580 \mathrm{~nm}$. The purpose of this is to block much of the visible radiation and prevent saturating of color camera, if used. When the radiant heater is used, a direct surface view of the fuel sample by a camera is not possible. The fuel surface can be viewed at a $45^{\circ}$ angle through the side tunnel window.

\section{Conclusions}

The FEANICS mini-facility will provide a research platform for the investigation of combustion of solids in microgravity on the International Space Station. This research will support NASA's Bioastronautics Initiative by improving our understanding of fire-safety in spacecraft. In order to meet the science requirements of current and future investigators, both the FEANICS and CIR project teams will work together to develop compatible and complimentary hardware. The FEANICS mini-facility will consist of two separate sets of hardware that will facilitate the combustion testing of thick and thin solid fuels, respectively. The thin fuel insert will accommodate both single, thin fuel sheets and continuous, flexible fuels on a roll. The thick fuel insert will accommodate single fuel samples up to 1.5 $\mathrm{cm}$ thick. The inserts. will contain a flow tunnel in which either quiescent or flow conditions can be produced. Opposed and concurrent flow testing will be possible with both inserts. Table 1 lists some of the pertinent hardware capabilities for the two inserts.

\section{References}

1. Otero, Angel M., "Multi-User Hardware Solutions to Combustion Science ISS Research", AIAA 2001-6527, Conference on International Space Station Utilization, Cape Canaveral, FL, 2001.

2. Myhre, Craig, "The Multi-user Droplet Combustion Apparatus", AIAA 2001-5043, Conference on International Space Station Utilization, Cape Canaveral, FL, 2001.

3. Jones, Jeffrey A. and A. P. Over, "Microgravity Gaseous Combustion Flight Hardware", AIAA 2001-5046, Conference on International Space Station Utilization, Cape Canaveral, FL, 2001.

4. O'Malley, Terence and K. Weiland, "The Fluids and Combustion Facility Combustion Integrated Rack: Microgravity Combustion Science on Board the International Space Station", AIAA 2001-4927, Conference on International Space Station Utilization, Cape Canaveral, FL, 2001. 



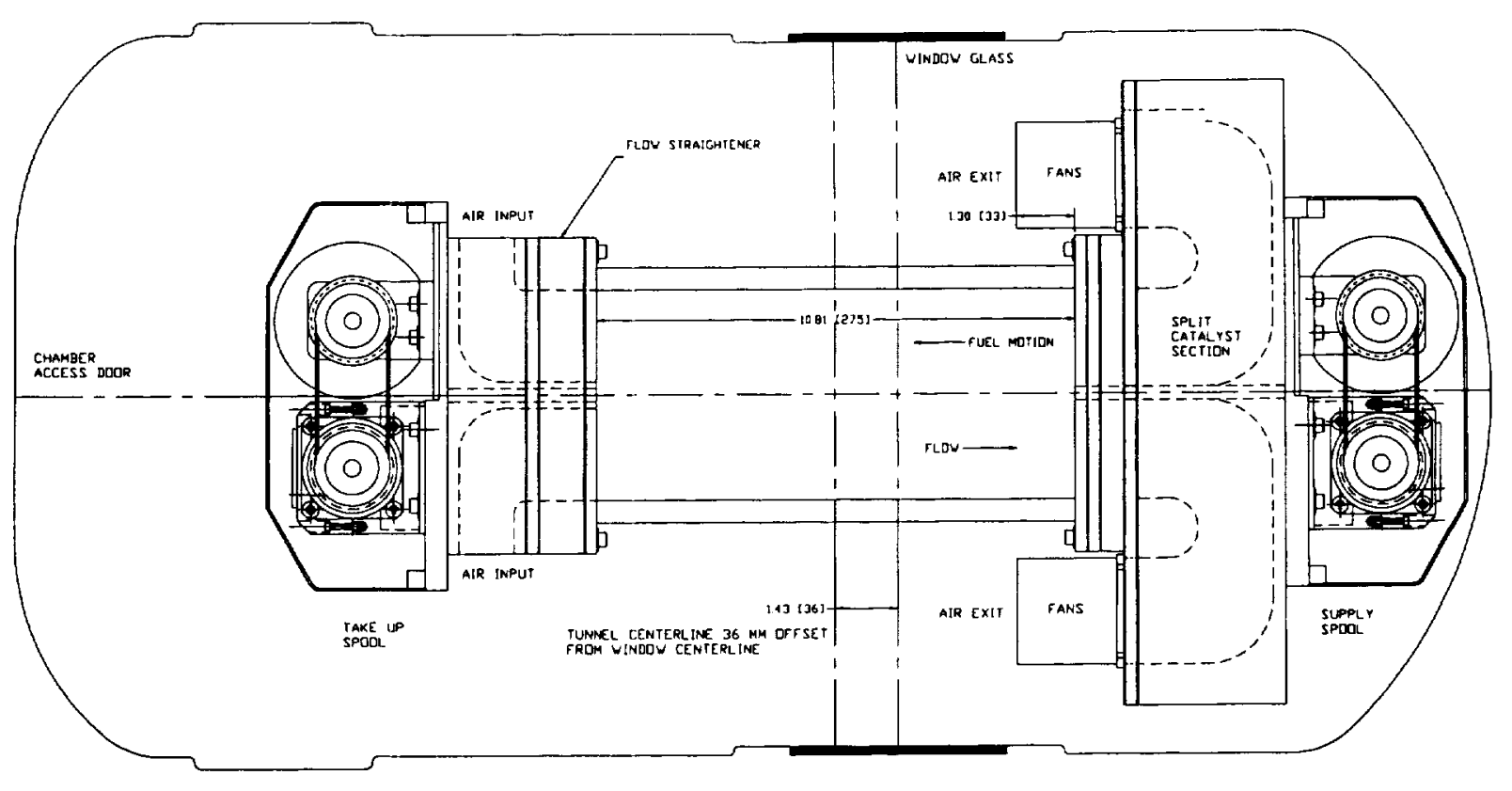

Figure 1. Thin Fuel Insert with Fuel Rolls.

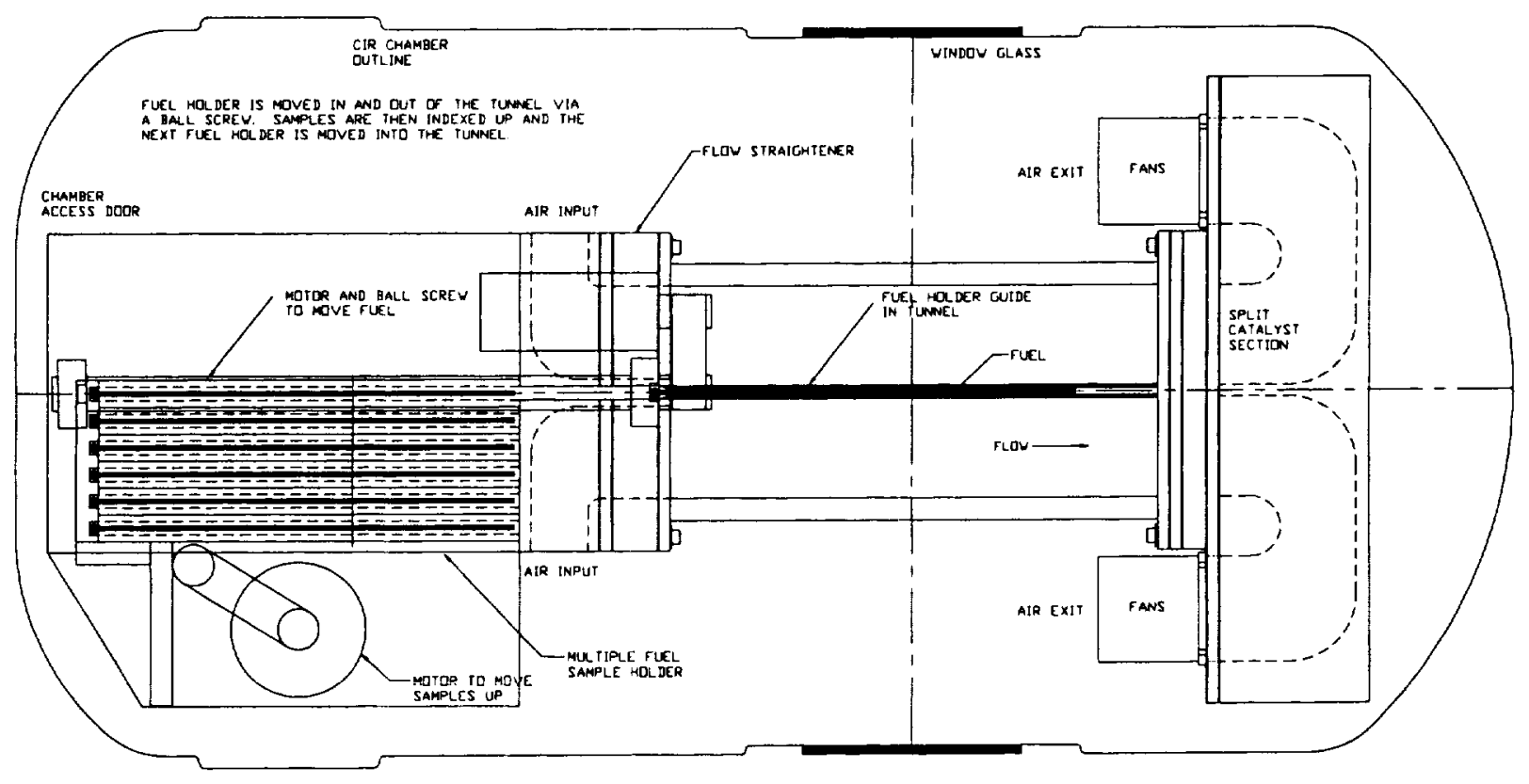

Figure 2. Thin Fuel Insert with End Loader. 



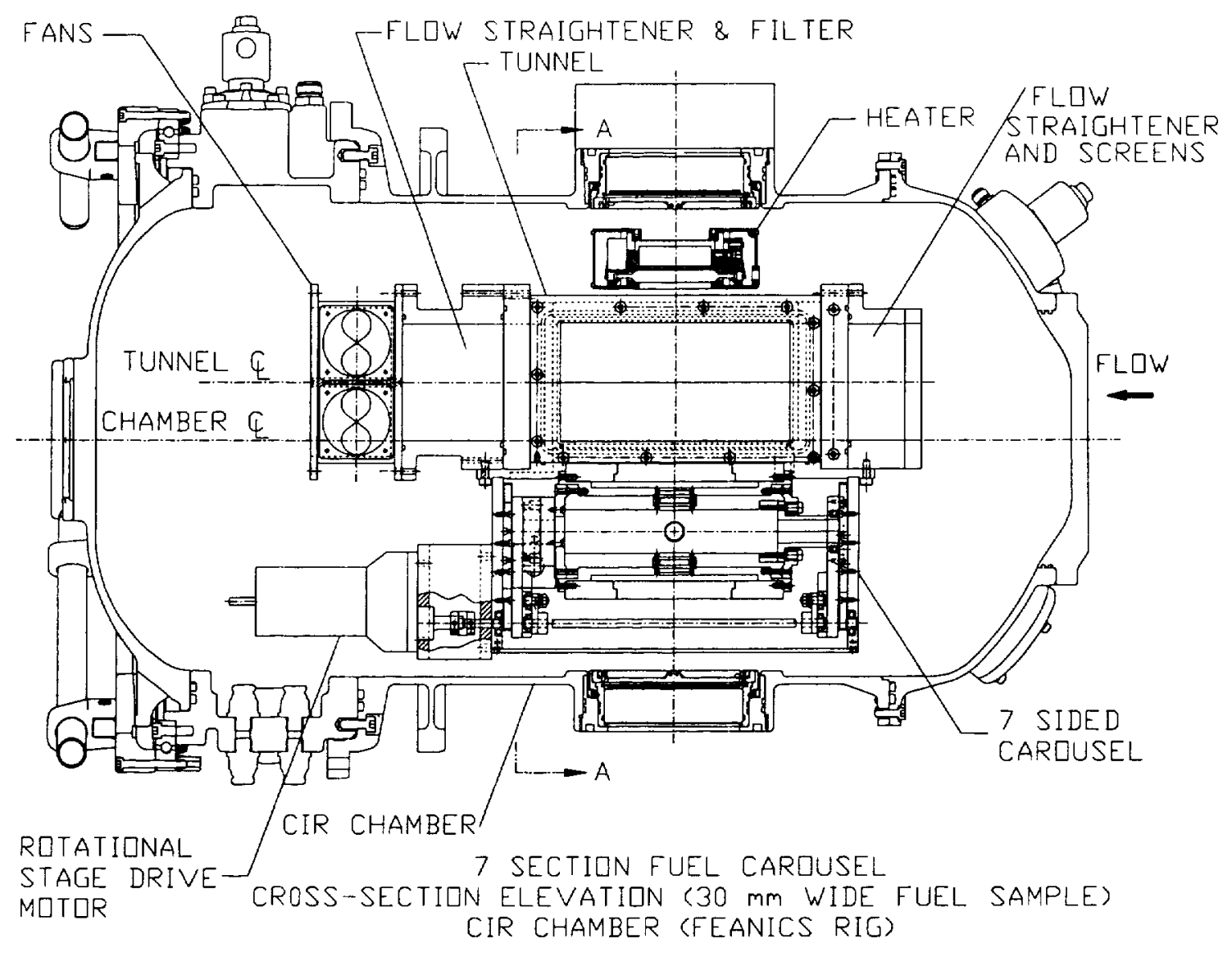

Figure 3. Thick Fuel Insert with Fuel Carousel and Radiant Heater.

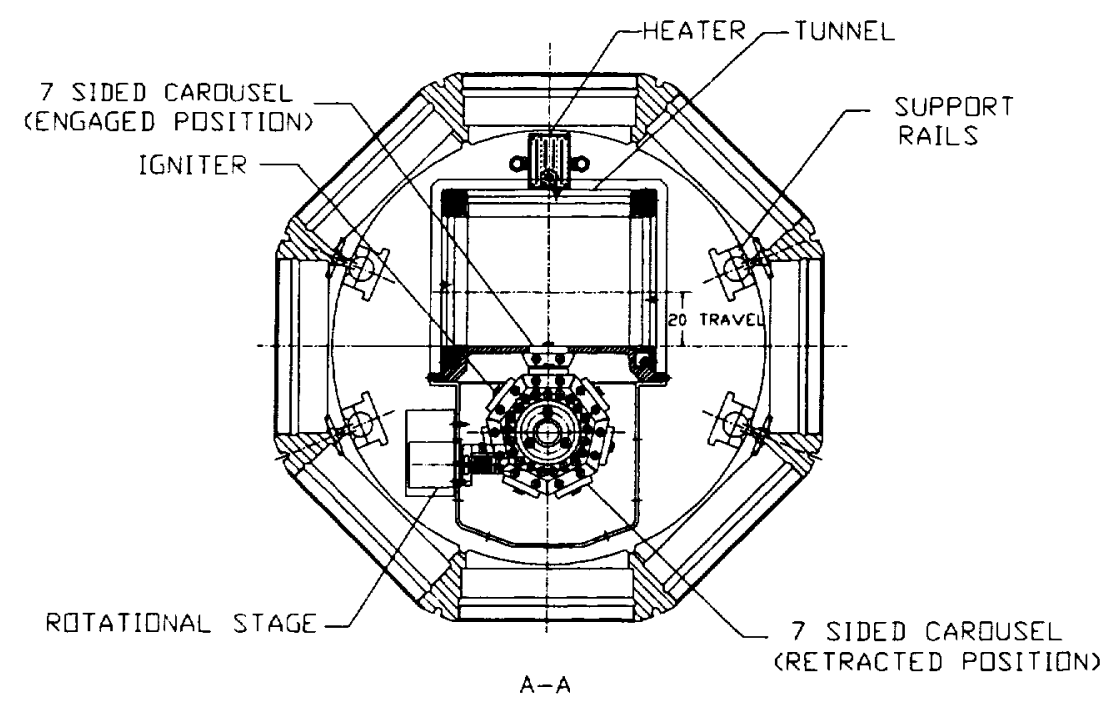

7 SECTION FUEL CAROUSEL

CRESS-SECTIDN ELEVATION ( $30 \mathrm{~mm}$ WIDE FUEL SAMPLE)
I_OOKING UPSTREAM

Figure 4. Thick Fuel Insert with 7-sided Fuel Carousel and Radiant Heater (End View) 
- 
Table 1. FEANICS Hardware Capability Summary

\begin{tabular}{|l|l|l|}
\hline & Thin Fuel Insert & Thick Fuel Insert \\
\hline Flow Velocity (cm/s) & $0-20$ & $0-20$ \\
\hline Flow Direction & Concurrent or Opposed & Concurrent or Opposed \\
\hline Test Gas Temperature (K) & $290-301$ & $290-301$ \\
\hline Test Pressure (atm) & $0.8-5.0$ & $0.8-5.0$ \\
\hline Oxygen Concentration (\%) & Flow Tests - up to 30\% \\
Quiescent Tests - up to 50\% & Qlow Tests - up to 30\% \\
\hline $\begin{array}{l}\text { Tunnel Dimensions (cm) } \\
\text { W x H x L }\end{array}$ & $15 \times 12 \times 30$ & $15 \times 12 \times 30$ \\
\hline $\begin{array}{l}\text { Maximum Sample Size (cm) } \\
\text { W x H x L }\end{array}$ & $\begin{array}{l}\text { Roll - 13 x 0.1 x 900 } \\
\text { End Loader - 14 x 1 x 17.8 }\end{array}$ & $12 \times 1.5 \times 20$ \\
\hline $\begin{array}{l}\text { Sample Location } \\
\text { Ignition Method }\end{array}$ & Center of Tunnel & Bottom of tunnel \\
\hline $\begin{array}{l}\text { Fuel Instrumentation } \\
\text { Low Light Level-IR Camera } \\
\text { Lolor Laght Level-UV Camera }\end{array}$ & $\begin{array}{l}\text { Roll - None Possible } \\
\text { End Loader - Limited }\end{array}$ & Hot Wire \\
\hline $\begin{array}{l}\text { Additional Hardware Provided by FEANICS: } \\
\text { Mid-IR Camera }\end{array}$ & \begin{tabular}{l} 
Instrumentation Possible \\
\hline
\end{tabular} & \\
\hline
\end{tabular}


